\title{
Bladder hematoma as an unusual cause or consequence of obstructed labour
}

\author{
Shikha Para, Shaveta Jain*, Daya Sirohiwal, Smiti Nanda
}

Department of Obstetrics and Gynaecology, Pt. B. D. Sharma PGIMS, Rohtak, Haryana, India

Received: 06 April 2021

Revised: 08 May 2021

Accepted: 10 May 2021

\author{
*Correspondence: \\ Dr. Shaveta Jain, \\ E-mail: parashikha22@gmail.com
}

Copyright: (C) the author(s), publisher and licensee Medip Academy. This is an open-access article distributed under the terms of the Creative Commons Attribution Non-Commercial License, which permits unrestricted non-commercial use, distribution, and reproduction in any medium, provided the original work is properly cited.

\begin{abstract}
Bladder hematoma is a rare complication but also an unusual mechanical cause of obstructed labour, whose incidence in India is $1-2 \%$. The most common reason for intraluminal urinary bladder hematoma is trauma, but it can occur with cystitis, pelvic malignancy and irradiation. A large hematoma may mimic a neoplastic mass on imaging. We reported a first case of bladder hematoma as a cause or result of obstructed labour in a multipara where the diagnosis was made intraoperatively. This bladder complication also became the indication for classical caesarean section, the technique which is almost obsolete nowadays, where the indication for classical caesarean section was obligatory.
\end{abstract}

Keywords: Bladder hematoma, Obstructed labor, Caesarean section

\section{INTRODUCTION}

Bladder hematoma is a very rare complication and also an unusual cause of obstructed labour out of the various other causes that causing mechanical obstruction. Incidence of obstructed labour, in the developing countries like India, the prevalence is about $1-2 \% .^{3}$ The most common reason for intraluminal urinary bladder hematoma is trauma others are cystitis and also in gynaecological and pelvic malignancies, the pelvic irradiation can affect non-targeted organs resulting in urogenital complications like hematoma. Large hematoma can mimic as neoplastic mass in imaging modalities. $^{2}$ Here we reported a case of bladder hematoma causing obstructed labour in a multipara where the diagnosis was made intraoperatively. This bladder complication also became the indication for classical caesarean section, the technique which almost obsolete nowadays. ${ }^{1-3}$

\section{CASE REPORT}

A 25 year old female gravida 2 with a previous full-term vaginal delivery was admitted as an emergency with labour pains at 38 weeks. She had premature rupture of membranes from the previous 13 hours and already had vigorous trial of vaginal delivery. She was unable to pass urine for over 8 hours. Her antenatal progress was uneventful. She had mild pregnancy induced hypertension but she was not taking any medication nor was there present or past history of urinary complaints.

At presentation, our patient was dehydrated but conscious and oriented. Apart from pallor, her general examination was normal with BP $120 / 90 \mathrm{~mm} / \mathrm{Hg}$, respiratory rate 21 per min and pulse 98 beats/min. Abdominal examination revealed a full-term uterus with longitudinal lie and cephalic presentation, a good sized baby, though the fetal heart was not heard, with the lower part of the abdomen distended, suggesting a full bladder. Vulval oedema was present. The cervix was fully dilated and fully effaced, 
membranes ruptured, but no liquor present, vertex presenting with large caput and a dry hot vagina. The bladder was catheterized but only $30 \mathrm{ml}$ of haemorrhagic urine was drained.

Investigations showed mild anaemia ( $\mathrm{Hb} 110 \mathrm{~g} / \mathrm{l})$, leucocytosis $(20 \times 109 / 1)$, normal platelet count $(300 \times 109$ /1), peripheral blood smear showing a dimorphic picture, bleeding time 2 min 10 seconds and clotting time 4 min 20 seconds, prothrombin time 14.8 seconds, international normalized ratio 1.04 and normal glucose, electrolyte and creatinine values.

An immediate caesarean section was scheduled. Intraoperative findings (Figure 1) showed ballooning of the urinary bladder, which was oedematous and very distended (as a 26 week sized uterus) with multiple dilated and congested blood vessels on its wall. The whole bladder occluded the lower uterine segment (Figure 2) forcing access through a classical incision. She delivered a female baby of $3.3 \mathrm{kgs}$ with Apgar score 1, 1, 6 at $0,1,5$ minutes after delivery. A 3-way Foley catheter for continuous bladder irrigation was inserted and around $70 \mathrm{cc}$ of haemorrhagic urine was drained and haemostasis gradually achieved spontaneously. Two units of packed red cells and four of fresh frozen plasma were transfused (intraoperative blood loss of around 1.5 litres). Continuous bladder irrigation was continued for 72 hours, with evacuation of clots by cystoscopy on two occasions, the catheter left in situ for 14 days, to prevent fistula development. Ultrasound scanning of the kidneys showed no dilation. Her postoperative recovery was uneventful.

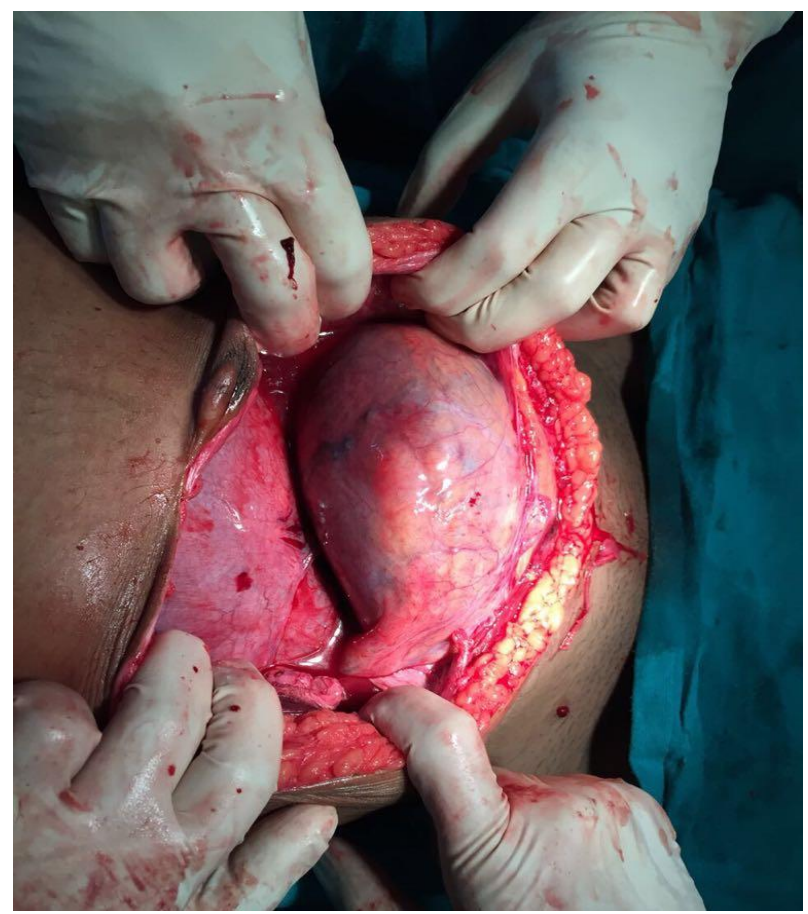

Figure 1: Distended bladder occluding whole of the lower uterine segment.

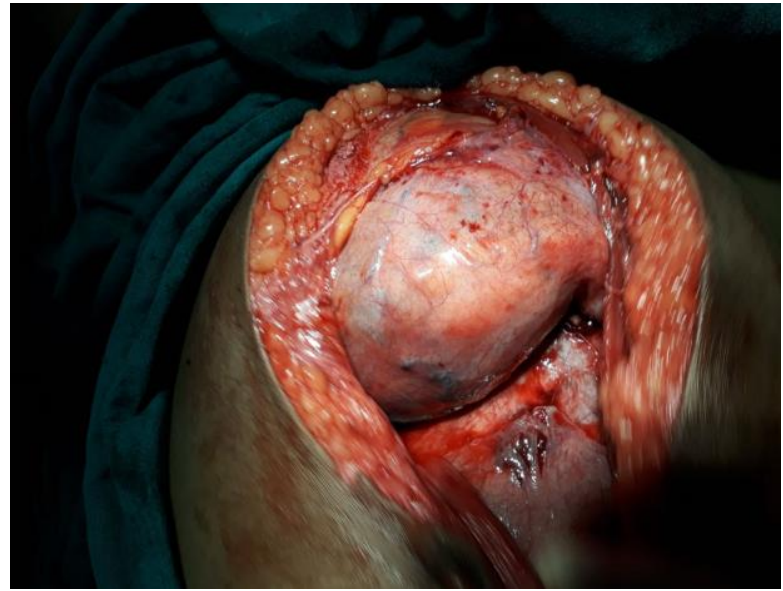

Figure 2: Multiple dilated and congested blood vessels on the bladder wall.

\section{DISCUSSION}

Obstructed labour is the one where inspite of good uterine contractions, the progressive descent of the presenting part is arrested due to mechanical obstruction. Bladder hematoma masquerading as neoplastic mass and become the unusual cause of obstructed labour and that of classical caesarean section. ${ }^{1}$ The most common causes of bladder hematoma is trauma, cystitis and post irradiation therapy in gynaecological malignancies. ${ }^{2}$ Intractable haematuria localizing to the bladder may range in severity from a transient condition that quickly resolves after conservative management to a lifethreatening condition requiring urgent intervention. Unfortunately, patients in this situation are often elderly, but we report it in young and antenatal female. ${ }^{2}$ Bladder hematoma was unexpected and unnoticed and diagnosis can be made by ultrasonography, where blood clots in the urinary bladder usually form echogenic masses without acoustic shadow and without visible blood flow in doppler and MRI pelvis will show a frond-like appearance of clot formation inside the urinary bladder. ${ }^{1}$ In the case of large lesions and unsure diagnosis, continuous bladder irrigation should be done. Classical caesarean section, the, indication for this operation in modern obstetrics are very few indeed. These include moribund patient with antepartum haemorrhage, lower segment inaccessible as in dense adhesion, gross kyphosis, cancer cervix. In this case report bladder hematoma was occupying the lower uterine segment, can also become the indication. ${ }^{3}$

\section{CONCLUSION}

Whenever bladder distended but no urine is coming out then think about bladder hematoma, we have to be cautious while doing LSCS in these cases to prevent bladder injury and lower uterine segment not seen think for delivering baby through upper segment means classical, in this way we can prevent bladder injuries. Maternal injuries during labour are largely preventable 
with proper understanding of the previous obstetric history, careful monitoring of the delivery process and prompt intervention before damage to tissue occurs. Prompt diagnosis and timely intervention is very important to prevent complication like vesicovaginal fistula and rupture uterus and in this case risk of infection, urinary retention, bladder injury and bladder rupture. Although very rare, when patient present with obstructed labour with gross haematuria, bladder hematoma can be the unusual cause, should be kept in mind while managing the patient. In such type of obstetrics complication classical caesarean can be done although obsolete nowadays.

Funding: No funding sources Conflict of interest: None declared Ethical approval: Not required

\section{REFERENCES}

1. Misra, R. Ian Donald's Practical Obstetric Problems. 7th ed. Gurugram: Wolters Kluwer India; 2014: 698.

2. Campbell M, Wein A, Kavoussi L, Partin A, Peters C, Walsh P. Campbell-Walsh Urology. 11th ed. Philadelphia: Elsevier: 2016.

3. Jain A, Mahato A, Jacob MJ, Vishnoi MG, Pandit AG, Solanki KP, et al. Hematoma in urinary bladder masquerading as neoplastic mass. Ind J Nuclear Med. 2018;33(3):253.

Cite this article as: Para S, Jain S, Sirohiwal D, Nanda S. Bladder hematoma as an unusual cause or consequence of obstructed labour. Int J Reprod Contracept Obstet Gynecol 2021;10:2531-3. 